\title{
Princely Virtues in the Middle Ages, 1200-1500, Edited by István P. Bejczy and Cary J. Nederman
}

\section{G. Matteo Roccati}

\section{(2) OpenEdition}

10 Journals

\section{Édition électronique}

URL : http://journals.openedition.org/studifrancesi/5856

DOI : 10.4000/studifrancesi.5856

ISSN : 2421-5856

Éditeur

Rosenberg \& Sellier

\section{Édition imprimée}

Date de publication : 1 mai 2011

Pagination : 146

ISSN : 0039-2944

\section{Référence électronique}

G. Matteo Roccati, «Princely Virtues in the Middle Ages, 1200-1500, Edited by István P. Bejczy and Cary

J. Nederman », Studi Francesi [En ligne], 163 (LV | I) | 2011, mis en ligne le 30 novembre 2015, consulté

le 13 janvier 2021. URL : http://journals.openedition.org/studifrancesi/5856 ; DOI : https://doi.org/

10.4000/studifrancesi.5856

Ce document a été généré automatiquement le 13 janvier 2021.

\section{(c)}

Studi Francesi è distribuita con Licenza Creative Commons Attribuzione - Non commerciale - Non opere derivate 4.0 Internazionale. 


\section{Princely Virtues in the Middle Ages, 1200-1500, Edited by István P. Bejczy and Cary J. Nederman}

\section{G. Matteo Roccati}

\section{RÉFÉRENCE}

Princely Virtues in the Middle Ages, 1200-1500, Edited by István P. Bejczy and Cary J.

Nederman, Turnhout, Brepols, 2007 («Disputatio», 9), pp. XII-318.

1 Le volume rassemble douze contributions couvrant une aire assez large, de l'Espagne aux pays germaniques. On signalera plus spécialement dans le cadre de cette rassegna les articles suivants.

2 István P. BEJCZY, The Concept of Political Virtue in the Thirteenth Century, pp. 9-32, étudie le concept de virtus politica chez différents auteurs des XII $^{\mathrm{e}}$-XIII ${ }^{\mathrm{e}}$ siècles, avant et après la réception des œuvres aristotéliciennes.

3 Michiel VERWEIJ, Princely Virtues or Virtues for Princes? William Peraldus and his "De eruditione principum", pp. 51-71, donne l'analyse du traité (contenu et sources), composé vers 1265 , et il souligne sa perspective religieuse et pastorale, indépendante de l'influence aristotélicienne.

4 Marco tOSTE, Virtue and the City: The Virtues of the Ruler and the Citizen in the Medieval Reception of Aristotle's "Politics", pp.73-98, étudie les commentaires d'Aristote et remarque avec justesse une certaine autonomie de la vertu de prudence, donc du politique, ce dernier étant conçu en continuité avec la morale, non dans une perspective qui annoncerait Machiavel.

5 Pamela KALNING (translated by Eric KUCHLE), Virtues and Exempla in John of Wales and Jacobus de Cessolis, pp. 139-176, relève de nombreux exempla communs au Breviloquium de 
virtutibus antiquorum principum et philosophorum et au Liber de ludo scaccorum (tableau aux pp. 160-176), ce qui fait supposer une dépendance directe.

6 Cary J. NEDERMAn, The Opposite of Love: Royal Virtue, Economic Prosperity, and Popular Discontent in Fourteenth-Century Political Thought, pp.177-199, s'intéresse à deux traités du XIV e siècle: le Speculum regis Edwardi III de Guillaume de Pagula et l'anonyme L'estat et le gouvernement comme les princes et seigneurs se doivent gouverner. Il examine la critique de l'action économique (fiscale) et politique du prince, critique lucide même si elle s'exprime dans les termes moraux traditionnels de l'amour entre le souverain et ses sujets.

7 Yelena MAzour-MAtusevich and István P. Bejczy, Jean Gerson on Virtues and Princely Education, pp.219-236, analyse la conception morale et religieuse de l'éducation princière dans deux traités en forme épistolaire adressés par Gerson, le premier au précepteur du dauphin Louis de Guyenne, le second à celui de Charles, futur Charles VII (Claro eruditori et Erunt omnes docibiles).

8 La bibliographie (pp. 281-306), l'index des manuscrits et celui des noms propres et des œuvres anonymes complètent le volume. 